\title{
Desempenho acústico de conjuntos de portas e paredes separadas pelo hall de entrada
}

\author{
Acoustic performance of door and wall sets separated by \\ entrance hall
}

\section{Claudio Trindade Scherer \\ Maria Fernanda de Oliveira \\ Daniel Reis Medeiros \\ Bernardo Fonseca Tutikian}

\section{Resumo}

${ }^{1}$ Claudio Trindade Scherer

${ }^{1}$ Universidade do Vale do Rio dos

Sinos

São Leopoldo - RS - Brasil

2 Maria Fernanda de OLiveira ${ }^{2}$ Universidade do Vale do Rio dos

São Leopoldo - RS - Brasil

${ }^{3}$ Daniel Reis Medeiros ${ }^{3}$ Universidade do Vale do Rio dos

São Leopoldo - RS - Brasil

${ }^{4}$ Bernardo Fonseca Tutikian ${ }^{4}$ Universidade do Vale do Rio dos

São Leopoldo - RS - Brasil

Recebido em 06/09/18

Aceito em 05/11/18

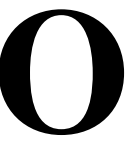

conjunto de paredes e portas separadas pela circulação de uso comum em edifícios residenciais passou a ter seu desempenho acústico avaliado, a partir da entrada em vigor da norma brasileira NBR 15575. Nesse contexto, este trabalho propõe determinar a influência das características dos elementos construtivos - portas e circulações entre unidades habitacionais - no isolamento ao ruído aéreo do conjunto de paredes e portas separadas pelo hall de entrada. Foram escolhidos três prédios e realizada uma série de ensaios de desempenho acústico em campo, abrangendo diversas situações. Também foram usados artifícios para a vedação das frestas das portas, a fim de verificar a melhora do desempenho do sistema. Os resultados obtidos apontam para a perda de desempenho acústico com o aumento das frestas entre a folha da porta e o piso. Ainda, foram encontradas relações entre o tempo de reverberação dos ambientes de circulação e a distância entre as portas de entrada das unidades habitacionais. Pode-se concluir que o alinhamento frontal de portas de entrada das unidades habitacionais distintas e halls com elevado tempo de reverberação reduzem a eficiência do isolamento acústico do conjunto de portas e parede voltadas para circulações de uso comum em edifícios habitacionais, assim como frestas mal vedadas.

Palavras-chave: Norma de desempenho. Conjunto de portas e paredes. Isolamento de ruído aéreo.

\section{Abstract}

The set of walls and doors separated by communal circulation areas in residential buildings began to have their acoustic performance evaluated since the Brazilian standard NBR 15575 was implemented. The aim of this paper is to determine the influence of the characteristics of the constructive elements - doors and corridors between housing units - on the insulation of the air noise of the set of walls and doors separated by the entrance hall. Three buildings were chosen and a series of acoustic performance tests were performed on the site, covering several situations. Devices were used to seal the door gaps in order to verify the improvement of the performance of the system. The results point to loss of acoustic performance with larger gaps between the door and the floor. In addition, a relationship was detected between the reverberation time of the circulation environments and the distance between the entrance doors of the housing units. The conclusion of the study is that frontal alignment of the entrance doors of the different housing units and corridors with high reverberation time as well as badly sealed gaps reduce the acoustic insulation efficiency of the set of doors and wall facing communal circulation areas in residential buildings.

Keywords: Performance standard. Set of wall and doors. Insulation to air noise. 


\section{Introdução}

Os sons gerados no interior dos edifícios podem ser particularmente incômodos quando produzidos por usuários de unidades habitacionais distintas, e o isolamento acústico de elementos e de sistemas construtivos pode garantir a privacidade adequada em edifícios residenciais (GARG; KUMAR; MAJI, 2013). As fontes de ruído no interior de edificações residenciais são, usualmente, decorrentes de atividades cotidianas, como a emissão sonora de aparelhos domésticos, além das ações dos próprios usuários ao falar, andar ou interagir com o ambiente (EGAN, 2014). No entanto, segundo Prato e Schiavi (2015), verifica-se um uso crescente de equipamentos de áudio e de vídeo cada vez mais potentes em ambientes residenciais, especialmente com o aprimoramento da reprodução do áudio dos sons graves em baixas frequências. Apesar do desenvolvimento e da popularização das fontes sonoras em ambientes residenciais, os sistemas construtivos ainda são dimensionados para realidades distintas. Além disso, segundo Duarte e Viveiros (2007), o aumento no uso de materiais leves e paredes menos espessas causou desde o século XIX uma perda de, aproximadamente, $20 \mathrm{~dB}$ no isolamento acústico de edificações residenciais brasileiras. Verifica-se, portanto, uma perspectiva de necessidade de qualificação da capacidade de isolamento acústico de sistemas construtivos, tanto pelo aumento do uso de sistemas leves como pela popularização de fontes de áudio mais potentes em ambientes residenciais.

As principais variáveis que afetam o isolamento acústico são a massa do sistema construtivo analisado, a frequência predominante do som incidente e a existência de pontos fracos em elementos construtivos, como portas e janelas (SCHIAVONI et al., 2016; THOMAS; DING, 2018). As características relacionadas à rigidez do sistema, o ângulo de incidência das ondas sonoras, e, no caso de o elemento ser constituído de várias camadas, a quantidade dessas, suas características de impedância e a distância entre elas.

O isolamento a sons aéreos também é assegurado por elementos como portas e paredes, que compõem os sistemas de compartimentação de uma edificação. Mateus e Pereira (2011) afirmam que a transmissão sonora entre dois compartimentos envolve diversos fatores, como as características elasto-dinâmicas dos elementos de separação, a heterogeneidade dos elementos, as características das ligações e dos campos sonoros estabelecidos nos recintos emissor e receptor. Além disso, a obtenção de um isolamento acústico eficiente depende da escolha de uma solução construtiva adequada e da correta instalação de aberturas, como portas e janelas (MAK; WANG, 2015; PATRÍCIO, 2010).

Segundo Hopkins (2012), nas portas sem quaisquer vedações, a transmissão sonora através das aberturas ao redor do perímetro da folha compromete a eficiência acústica de todo o sistema de vedação. As frestas causam uma diminuição significativa no índice de redução sonora nas faixas de frequências médias e altas, pois o isolamento acústico será comprometido a partir da banda de frequência, em hertz, relacionada ao comprimento de onda. Quanto menor a fresta, mais próximo às altas frequências ficará o início da perda de eficiência do elemento construtivo.

Atingir a adequada eficiência acústica de uma porta pode ser uma tarefa complexa, pois a qualidade de cada componente é importante para o seu desempenho. Basicamente, existem duas partes a serem consideradas no projeto de portas acústicas, sendo a perda de transmissão sonora da folha, ou parte móvel, e a estanqueidade do sistema de vedação. O sistema de vedação, segundo Jones (2008), é o mais crítico dos dois. As portas e seus sistemas de vedação requerem detalhes e especificações para a sua construção e, muitas vezes, são o ponto fraco de um sistema de vedação vertical (SCHVARSTZHAUPT; TUTIKIAN; NUNES, 2014; HERRERA; RECUERO, 2010).

Pião, Godinho e Tadeu (2008) estudaram o comportamento acústico de paredes de alvenaria com pequenas aberturas de $36 \mathrm{~cm}^{2}$, caracterizadas como elementos que podem compor partes de instalações técnicas de água, esgoto ou eletricidade e, por causa de sua inserção na alvenaria, determinar uma heterogeneidade para a transmissão sonora no sistema de vedação. Uma parede de alvenaria revestida com espessura final de $11 \mathrm{~cm}$ pode ter seu isolamento acústico comprometido, com quedas de até $10 \mathrm{~dB}$ no isolamento acústico. Foi observado que as perdas de isolamento apresentaram os valores mais elevados nas frequências mais altas, e que, entre todas as amostras ensaiadas, com 0 aumento da frequência diminuiu o isolamento. Esse comportamento indicou que a existência de pontos fracos em uma parede se fez sentir para menores comprimentos de onda.

Em edifícios habitacionais as portas internas com maior exigência de isolamento acústico estão instaladas em sistemas de vedações verticais que separam as áreas privativas das áreas de uso comum internas (KLIPPEL FILHO et al., 2016). No Brasil, o desempenho acústico desses sistemas está contemplado nas avaliações entre unidades habitacionais distintas, separadas pela circulação 
horizontal de uso comum, ou seja, conjunto de paredes e portas separadas pelo hall. Nesse contexto, as paredes com grande distância entre si, como o conjunto de paredes e portas separadas por hall, apresentam forte influência da absorção sonora do ambiente que as separa, com uma importante contribuição no resultado da perda de transmissão acústica, principalmente devido à influência da distância da fonte sonora em relação ao receptor (MAK; WANG, 2015). Segundo Hopkins (2012), existe uma relação entre a densidade de energia, devido aos campos direto e reverberante em uma sala de $50 \mathrm{~m}^{3}$, com distâncias de até $1 \mathrm{~m}$ da fonte de som. À medida em que a distância da fonte aumenta, para distâncias maiores que $0,50 \mathrm{~m}$, o campo reverberante assume maior importância na contribuição do campo sonoro total.

Os estudos teóricos sobre a propagação do som em ambientes estreitos como corredores de circulações horizontais se fundamentam em um modelo simples e podem ser considerados como se fossem um corredor de comprimento infinito, dividido em uma série de seções transversais em forma de caixas muito finas (PETERS; SMITH; HOLLINS, 2013; ANTÓNIO; TADEU; GODINHO, 2003). Nessa consideração teórica existe uma grande quantidade de campos sonoros bidimensionais que são acoplados ao longo do comprimento desse corredor. Esse modelo aplica-se a um corredor infinitamente longo, ou seja, sem extremidades, com a propagação do som na direção longitudinal No entanto, na prática, o som será parcialmente refletido e parcialmente absorvido do final do corredor e a propagação do som pode não ocorrer no sentido estritamente longitudinal desse ambiente (MATSUDA et al., 2017; CHO et al., 2018).

Na maioria dos países da Europa, os regulamentos de construção especificam os requisitos mínimos sobre condições acústicas para novas residências e um esquema de classificação com classes que refletem diferentes níveis de conforto acústico (PATRÍCIO, 2005). Além dos critérios com valores mínimos para isolamento acústico aéreo, valores máximos para nível de pressão sonora de impacto e níveis de pressão sonora de equipamentos prediais, também são considerados valores máximos de tempo de reverberação para áreas de circulação de uso comum, como escadas e circulações horizontais (RASMUSSEN, 2016). Nessa classificação, quanto maior o tempo de reverberação das áreas de circulação de uso comum, pior o desempenho acústico do ambiente, com variações de 2,1 s para o critério mínimo e 0,6 s para a classe mais restritiva. Ressalta-se que, conforme Zannin et al. (2005), o tempo de reverberação elevado é causado pelo excesso de reflexão das superfícies de um ambiente fechado e compromete o bom entendimento da comunicação oral. Ainda, segundo Rasmussen (2016), o tempo de reverberação nessas áreas de uso comum destinadas à circulação é analisado por um valor único, determinado pela média aritmética dos tempos de reverberação nas bandas em $250 \mathrm{~Hz}$ e $2.000 \mathrm{~Hz}$.

O objetivo deste trabalho é determinar a influência das circulações de uso comum e das frestas das portas no isolamento sonoro entre duas unidades habitacionais distintas, separadas pelo hall de entrada.

\section{Método}

\section{Procedimentos de medições}

O método de medição para o som aéreo em campo está descrito na ISO 16283-1 (INTERNATIONAL..., 2014) e é baseado na emissão de um som padrão em um ambiente denominado emissor, através de uma fonte sonora omnidirecional e medição dos níveis de pressão sonora em bandas de terço de oitava de $100 \mathrm{~Hz}$ a $3.150 \mathrm{~Hz}$ no ambiente adjacente receptor. As medições no ambiente emissor e receptor foram realizadas simultaneamente, com dois canais. Conforme recomendações da norma ISO 16283-1 (INTERNATIONAL..., 2014), o tempo de reverberação foi medido nos ambientes de recepção, seguindo recomendações da norma ISO 3382-2 (INTERNATIONAL..., 2008). A diferença entre os níveis sonoros, com uma correção segundo as condições acústicas do recinto receptor, resultam na diferença de níveis padronizada $\left(\mathrm{D}_{\mathrm{nT}}\right)$, que é convertida em um número único através da ISO 717-1 (INTERNATIONAL..., 2013), obtendo a diferença padronizada de nível ponderada $\left(\mathrm{D}_{\mathrm{nT}, \mathrm{w}}\right)$.

Os equipamentos usados para as medições, da marca Brüel \& Kjaer, foram: analisador sonoro modelo 2270, classe de precisão 1; calibrador acústico modelo 4231, classe de precisão 1; microfone modelo 4189; amplificador de potência modelo 2734; fonte sonora omnidirecional modelo 4292; e software Qualifier type 7830, versão 2.18.6.

Também foram medidas as frestas com o auxílio de um paquímetro digital, em dois pontos, um em cada lado das portas na parte inferior das folhas, a $10 \mathrm{~cm}$ da extremidade. Foi feita a média aritmética dos valores das duas medidas para considerar como a fresta média na análise dos resultados.

\section{Objetos de estudo}

Foram realizados ensaios em 3 edifícios habitacionais, o A, B e C, de três construtoras de Porto Alegre (RS) e região metropolitana. As situações consideradas para este estudo foram para 
medições entre os apartamentos (AP) e o hall (Figura 1a), entre apartamentos com as portas alinhadas (Figura 1b) e entre apartamentos com as portas não alinhadas (Figura 1c).

\section{Prédio A}

$\mathrm{O}$ prédio A é composto do pavimento térreo, do $2^{\circ}$ pavimento com garagens e área de uso comum e de 10 pavimentos tipo, e os ensaios foram realizados no $4^{\circ}$ e $5^{\circ}$ pavimentos. No $4^{\circ}$ pavimento foram realizados ensaios entre as unidades e o hall de entrada e entre as unidades separadas pelo hall de entrada. A Figura 2 mostra os apartamentos do $4^{\circ}$ pavimento, com destaque para aqueles que foram usados nos ensaios, bem como áreas e volumes de ambientes e as distâncias entre os eixos das portas.

No $5^{\circ}$ pavimento foram realizados ensaios entre as unidades e o hall de entrada e entre as unidades separadas pelo hall de entrada. A Figura 3 mostra os apartamentos do pavimento, com destaque para aqueles que foram usados nos ensaios, bem como áreas e volumes de ambientes e as distâncias entre os eixos das portas.

Figura 1 - Esquema geral das situações consideradas nos ensaios em campo

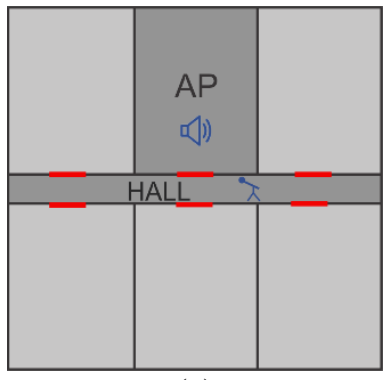

(a)



(b)

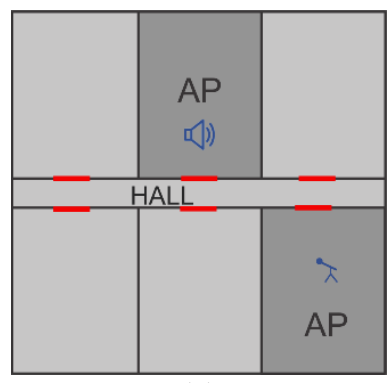

(c)

Figura 2 - Planta baixa do $4 \stackrel{0}{9}$ pavimento do prédio A

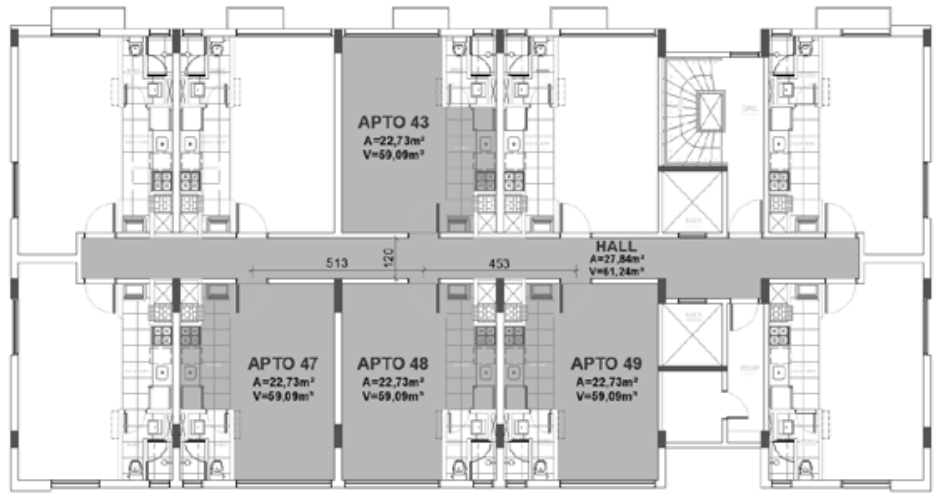

Figura 3 - Planta baixa do 5 pavimento do prédio A

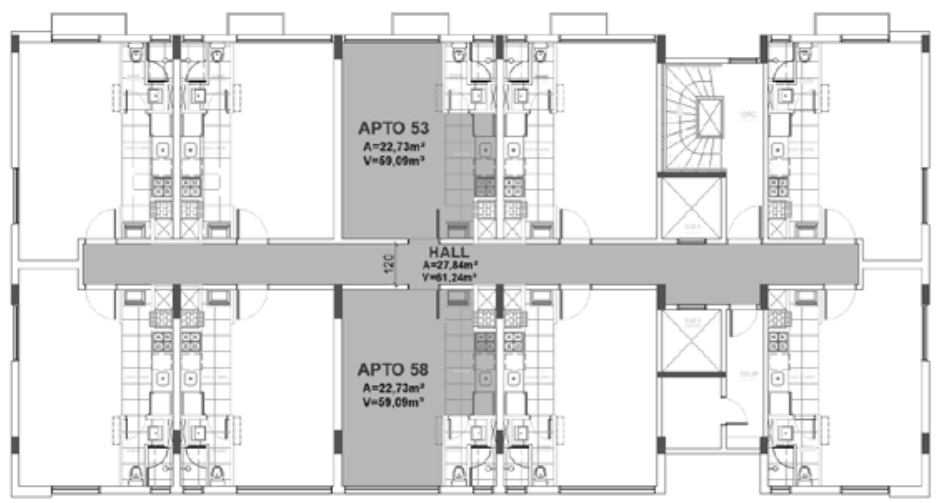


As paredes que dividiam os apartamentos do hall de entrada são compostas de blocos cerâmicos de vedação, com $14 \mathrm{~cm}$ de largura, com revestimento argamassado de $1 \mathrm{~cm}$ em cada face, totalizando 16 cm de largura. A porta de entrada é de madeira, com dimensão de $90 \mathrm{~cm} \times 210 \mathrm{~cm}$, e espessura de 35 mm. A porta é composta de lâmina base de madeira pinus de $4 \mathrm{~mm}$, lâmina capa com 0,6 mm e enchimento maciço com sarrafos em pinus e encabeçamento lateral com madeira dura. Nos pontos de contato da folha da porta com o batente foi utilizada borracha de vedação. A massa da folha da porta é de $30 \mathrm{~kg}$.

O hall de entrada possui uma largura de $1,20 \mathrm{~m}$, comprimento de $23,20 \mathrm{~m}$ e pé direito de $2,20 \mathrm{~m}$. O piso é cerâmico, nas paredes foi executada textura e o forro é rebaixado em gesso comum.

O tempo de reverberação do hall de entrada do prédio A está apresentado na Tabela 1.

Na Tabela 2 estão identificados os valores das frestas medidas em cada lado da folha de cada porta e as médias das espessuras das portas do $4^{\circ}$ e do $5^{\circ}$ pavimento do prédio A.

\section{Prédio B}

O prédio B é constituído por pavimento térreo e 4 pavimentos tipo. O sistema construtivo utilizado é de alvenaria estrutural com blocos cerâmicos. A Figura 4 apresenta uma planta baixa do pavimento tipo, e os ensaios foram realizados no $2^{\circ}$ pavimento.

As paredes que dividiam os apartamentos do hall de entrada são compostas de blocos cerâmicos estruturais, com $14 \mathrm{~cm}$ de largura e $7 \mathrm{MPa}$ de resistência à compressão, com revestimento argamassado de $1 \mathrm{~cm}$ em cada face da parede, com $16 \mathrm{~cm}$ de largura total. A porta de entrada é de madeira, com dimensões de $90 \mathrm{~cm}$ x $210 \mathrm{~cm}$, com espessura total de $35 \mathrm{~mm}$. A porta é semioca, estruturada em madeira, com contracapa de $3 \mathrm{~mm}$, batente de $35 \mathrm{~mm}$ de espessura e guarnições reguláveis em ambos os lados, todos componentes com revestimento melamínico. Em todo o perímetro da folha da porta foi utilizada borracha de amortecimento para os batentes. A massa da folha da porta é de $27 \mathrm{~kg}$.

\section{Tabela 1 - Tempo de reverberação do hall de entrada do prédio A}

\begin{tabular}{c|c|c|c|c|c|c|c|c|c|c|c|c|c|c|c|c}
\hline $\begin{array}{c}\text { Bandas de } \\
\begin{array}{c}\text { Frequências } \\
\text { (Hz) }\end{array}\end{array}$ & $\mathbf{1 0 0}$ & $\mathbf{1 2 5}$ & $\mathbf{1 6 0}$ & $\mathbf{2 0 0}$ & $\mathbf{2 5 0}$ & $\mathbf{3 1 5}$ & $\mathbf{4 0 0}$ & $\mathbf{5 0 0}$ & $\mathbf{6 3 0}$ & $\mathbf{8 0 0}$ & $\mathbf{1 k}$ & $\mathbf{1 , 2 5 k}$ & $\mathbf{1 , 6 k}$ & $\mathbf{2 k}$ & $\mathbf{2 , 5 k}$ & $\mathbf{3 , 1 5 k}$ \\
\hline TR (s) & 1,4 & 1,7 & 1,6 & 1,3 & 1,1 & 1,1 & 1,0 & 1,0 & 1,1 & 1,2 & 1,3 & 1,3 & 1,3 & 1,4 & 1,3 & 1,2 \\
\hline
\end{tabular}

Tabela 2 - Frestas das portas do 4 pavimento do prédio A

\begin{tabular}{c|c|c|c}
\hline Apartamento & $\begin{array}{c}\text { Espessura da fresta } \\
\text { fechadura (mm) }\end{array}$ & $\begin{array}{c}\text { Espessura da fresta } \\
\text { dobradiça } \mathbf{( m m})\end{array}$ & $\begin{array}{c}\text { Espessura média } \\
\text { da fresta (mm) }\end{array}$ \\
\hline A43 & 7,50 & 8,27 & 7,89 \\
A47 & 7,46 & 7,86 & 7,66 \\
A48 & 9,29 & 10,85 & 10,07 \\
A49 & 8,36 & 7,53 & 7,95 \\
A53 & 8,97 & 9,07 & 9,02 \\
A58 & 10,49 & 11,07 & 10,78 \\
\hline
\end{tabular}

Figura 4 - Planta baixa do 2 o pavimento do prédio B

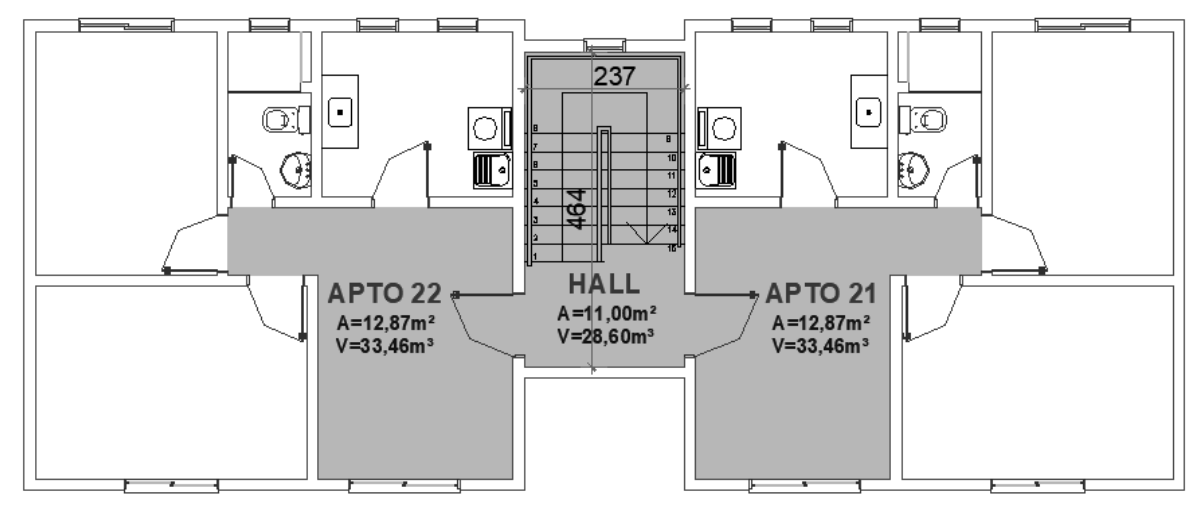


O hall de entrada possui uma largura de 2,37 m, comprimento de $4,64 \mathrm{~m}$ e pé-direito de $2,60 \mathrm{~m}$. O piso é cerâmico, nas paredes e teto foi executado revestimento argamassado e pintura.

O tempo de reverberação do hall de entrada do prédio B está apresentado na Tabela 3.

As espessuras das frestas entre a porta e o piso estão demonstradas na Tabela 4.

\section{Prédio C}

O terceiro prédio utilizado neste estudo, prédio C, apresenta o pavimento térreo e 4 pavimentos tipo. O sistema construtivo utilizado é de alvenaria estrutural com blocos de concreto. Os ensaios foram realizados no $2^{\circ}$ e $3^{\circ}$ pavimentos.

No $2^{\circ}$ pavimento foram realizados ensaios entre as unidades e o hall de entrada e entre as unidades separadas pelo hall de entrada. A Figura 5 mostra os apartamentos do pavimento, com destaque para aqueles que foram usados nos ensaios, bem como áreas e volumes de ambientes e as distâncias entre os eixos das portas.
As paredes que dividem os apartamentos do hall de entrada são compostas de blocos estruturais de concreto, com $14 \mathrm{~cm}$ de largura e $4 \mathrm{MPa}$ de resistência à compressão, com revestimento argamassado de $2 \mathrm{~cm}$ em cada face da parede, totalizando $18 \mathrm{~cm}$ de largura. A porta de madeira, com dimensão de $80 \mathrm{~cm} \mathrm{x} 210 \mathrm{~cm}$ e espessura de 35 $\mathrm{mm}$, é semioca, com quadro na espessura de 29,5 $\mathrm{mm}$, preenchimento sarrafeado e recoberta com chapas de HDF de $3 \mathrm{~mm}$. Em todo o perímetro da folha da porta foi instalada borracha de amortecimento para os batentes. A massa da folha da porta é de 13,65 kg.

O hall de entrada tem largura de $2,50 \mathrm{~m}$, comprimento de $6,96 \mathrm{~m}$ e pé-direito de $2,30 \mathrm{~m}$. O piso é cerâmico, nas paredes foi executada textura e o forro é rebaixado em gesso. O tempo de reverberação do hall de entrada do prédio C está apresentado na Tabela 5.

Foram medidas as frestas entre a porta e o piso, conforme demonstrado na Tabela 6 para o $2^{\circ}$ e $3^{\circ}$ pavimentos.

\section{Tabela 3 - Tempo de reverberação do hall de entrada do prédio B}

\begin{tabular}{c|c|c|c|c|c|c|c|c|c|c|c|c|c|c|c|c}
\hline $\begin{array}{c}\text { Bandas de } \\
\begin{array}{c}\text { Frequências } \\
\text { (Hz) }\end{array}\end{array}$ & $\mathbf{1 0 0}$ & $\mathbf{1 2 5}$ & $\mathbf{1 6 0}$ & $\mathbf{2 0 0}$ & $\mathbf{2 5 0}$ & $\mathbf{3 1 5}$ & $\mathbf{4 0 0}$ & $\mathbf{5 0 0}$ & $\mathbf{6 3 0}$ & $\mathbf{8 0 0}$ & $\mathbf{1 k}$ & $\mathbf{1 , 2 5 k}$ & $\mathbf{1 , 6 k}$ & $\mathbf{2 k}$ & $\mathbf{2 , 5 k}$ & $\mathbf{3 , 1 5 k}$ \\
\hline TR (s) & 3,2 & 3,2 & 3,2 & 2,6 & 2,5 & 2,7 & 2,8 & 2,8 & 2,8 & 2,7 & 2,7 & 2,8 & 2,7 & 2,5 & 2,3 & 2,0 \\
\hline
\end{tabular}

Tabela 4 - Frestas das portas do $2 \cong$ pavimento do prédio B

\begin{tabular}{c|c|c|c}
\hline Apartamento & $\begin{array}{c}\text { Espessura da fresta } \\
\text { fechadura (mm) }\end{array}$ & $\begin{array}{c}\text { Espessura da fresta } \\
\text { dobradiça (mm) }\end{array}$ & $\begin{array}{c}\text { Espessura média } \\
\text { da fresta (mm) }\end{array}$ \\
\hline B21 & 6,79 & 7,75 & 7,27 \\
B22 & 8,50 & 9,14 & 8,82 \\
\hline
\end{tabular}

Figura 5 - Planta baixa do 29 pavimento do prédio C

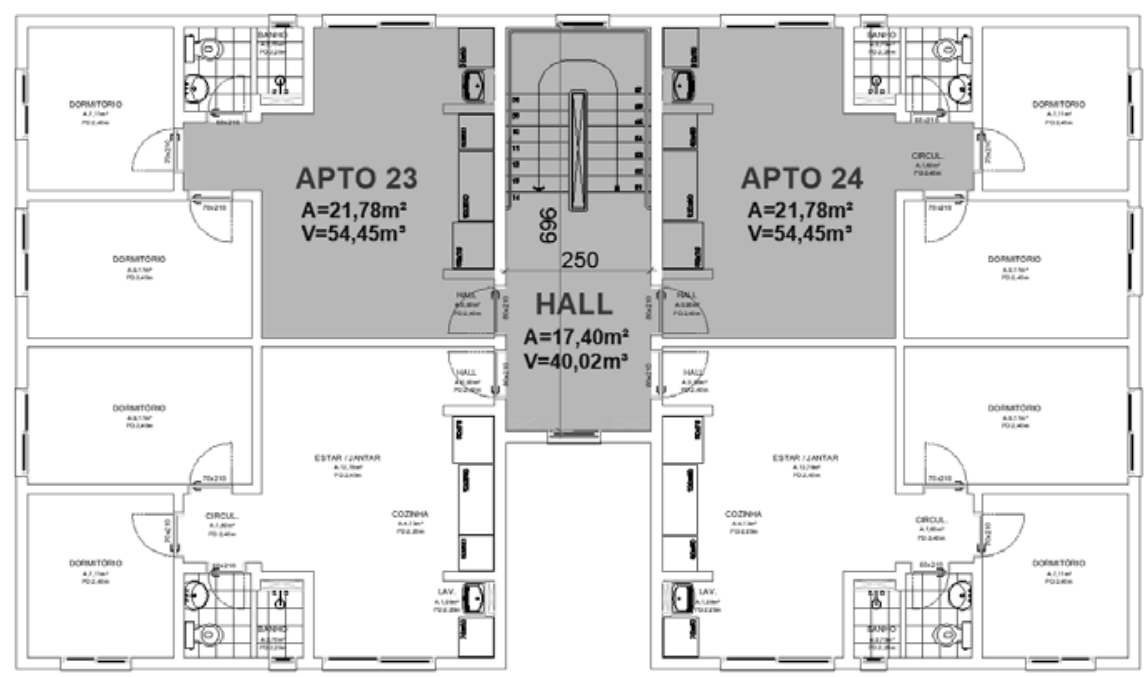


Tabela 5 - Tempo de reverberação do hall de entrada do prédio C

\begin{tabular}{c|c|c|c|c|c|c|c|c|c|c|c|c|c|c|c|c}
\hline $\begin{array}{c}\text { Bandas de } \\
\text { frequências } \\
\text { (Hz) }\end{array}$ & $\mathbf{1 0 0}$ & $\mathbf{1 2 5}$ & $\mathbf{1 6 0}$ & $\mathbf{2 0 0}$ & $\mathbf{2 5 0}$ & $\mathbf{3 1 5}$ & $\mathbf{4 0 0}$ & $\mathbf{5 0 0}$ & $\mathbf{6 3 0}$ & $\mathbf{8 0 0}$ & $\mathbf{1 k}$ & $\mathbf{1 , 2 5 k}$ & $\mathbf{1 , 6 k}$ & $\mathbf{2 k}$ & $\mathbf{2 , 5 k}$ & $\mathbf{3 , 1 5 k}$ \\
\hline TR (s) & 1,8 & 1,8 & 1,9 & 2,1 & 1,9 & 2,1 & 2,0 & 2,0 & 1,9 & 1,9 & 2,0 & 2,0 & 1,9 & 1,7 & 1,6 & 1,4 \\
\hline
\end{tabular}

Tabela 6 - Frestas das portas do $2^{\circ}$ e do $3^{\circ}$ pavimento do prédio $\mathrm{C}$

\begin{tabular}{c|c|c|c}
\hline Apartamento & $\begin{array}{c}\text { Espessura da fresta } \\
\text { fechadura }(\mathbf{m m})\end{array}$ & $\begin{array}{c}\text { Espessura da fresta } \\
\text { dobradiça } \mathbf{( m m})\end{array}$ & $\begin{array}{c}\text { Espessura média } \\
\text { da fresta (mm) }\end{array}$ \\
\hline C23 & 7,74 & 9,52 & 8,63 \\
C24 & 11,64 & 8,58 & 10,11 \\
C31 & 8,87 & 8,43 & 8,65 \\
C32 & 9,62 & 12,80 & 11,21 \\
C33 & 7,50 & 9,24 & 8,37 \\
C34 & 9,82 & 9,83 & 9,83 \\
\hline
\end{tabular}

Figura 6 - Dispositivo veda-porta utilizado: (a) com a porta aberta, (b) com a porta fechada e (c) vista do hall

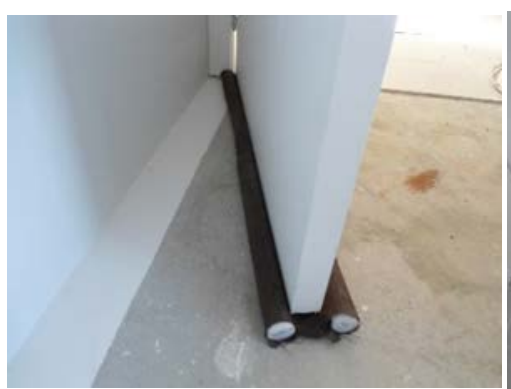

(a)

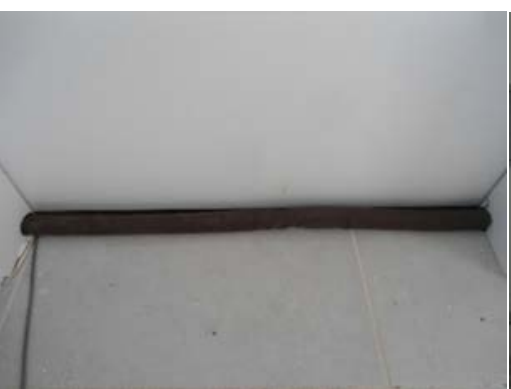

(b)

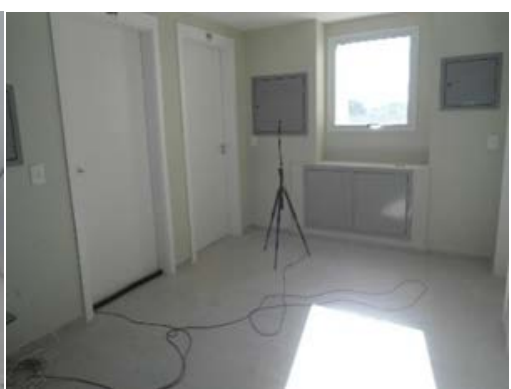

(c)
No $3^{\circ}$ pavimento foram realizados ensaios para verificar a melhora do isolamento ao ruído aéreo com a utilização de um dispositivo móvel vedaporta, confeccionado com tecido e dois cilindros de poliuretano expandido (Figura 6). O dispositivo foi posicionado abaixo da porta e, depois que ela foi fechada, o dispositivo foi puxado e pressionado contra a folha da porta.

\section{Resultados}

\section{Prédio A}

Os ensaios no prédio A foram realizados em dois pavimentos entre unidades habitacionais e o hall, entre unidades habitacionais em lados opostos do hall e unidades habitacionais adjacentes laterais.

\section{Ensaios realizados no $4^{\circ}$ pavimento do prédio A}

O isolamento ao ruído aéreo entre o apartamento A43 e o hall e entre o apartamento A48 e o hall mostra um comportamento muito semelhante, com uma frequência de ressonância bem definida na banda de $160 \mathrm{~Hz}$, conforme demonstrado na Figura 7. Observa-se que essa ressonância não ocorreu quando o ensaio foi feito entre as unidades separadas pelo hall de entrada, que apresentou um isolamento crescente até os $630 \mathrm{~Hz}$ e depois dessa banda de frequência começou a cair, em função das frestas das portas.

O isolamento entre A43 e o hall foi $1 \mathrm{~dB}$ superior ao isolamento de A48-hall, o que pode ser considerado dentro da margem de incerteza de medição.

Também foi realizado o ensaio de isolamento ao ruído aéreo entre os apartamentos situados em lados opostos da circulação (A43-A48, A43-A47 e A43A49), separados pelo hall de entrada, conforme demonstrado na Figura 8.

Nos três casos se observa a perda de isolamento entre as faixas de $630 \mathrm{~Hz}$ e $1.600 \mathrm{~Hz}$, em que a perda é maior. No caso dos resultados de isolamento entre os apartamentos A43 e A48, nos quais as portas estão alinhadas de frente uma para a outra, o resultado foi de $46 \mathrm{~dB}$, com valor menor que os outros casos, em que as portas estão desalinhadas. Entre A43-A47, a distância entre os eixos das portas é de $5,13 \mathrm{~m}$, e o isolamento foi de $52 \mathrm{~dB}$, enquanto que entre as unidades habitacionais A43-A49, a distância entre portas é de 4,53 m, e o resultado foi 
de $51 \mathrm{~dB}$. Essa diferença de $1 \mathrm{~dB}$ entre os resultados dos sistemas com as portas não alinhadas pode ser considerada dentro da margem de incerteza de medição. Ainda, em relação aos resultados de A43A47 e A43-A49, pode-se ter uma expectativa de valores semelhantes por bandas de terço de oitava, mas a maior representatividade da semelhança de situação geométrica dos sistemas está expressa nos valores ponderados. Essa diferença pode ser explicada pelo aumento da distância de $60 \mathrm{~cm}$ entre os eixos de portas nas duas situações. Dessa forma, pode-se indicar que o não alinhamento das portas de entrada das unidades habitacionais pode contribuir para a qualificação do desempenho acústico desses sistemas construtivos.

\section{Ensaios realizados no 5\% pavimento do prédio $A$}

O isolamento ao ruído aéreo entre o apartamento A53 e o hall e entre o apartamento A58 e o hall mostra um comportamento muito semelhante, conforme demonstrado na Figura 9.

O isolamento entre A53-hall e A58-hall obteve o mesmo resultado de $25 \mathrm{~dB}$, com frestas de 9,02 mm e $10,78 \mathrm{~mm}$, respectivamente. O valor do isolamento entre as unidades separadas pelo hall de entrada foi de $46 \mathrm{~dB}$, resultados muito parecidos aos do $4^{\circ}$ pavimento.

Figura 7 - Resultados entre ambientes: A43-hall, A48-hall e A43-A48

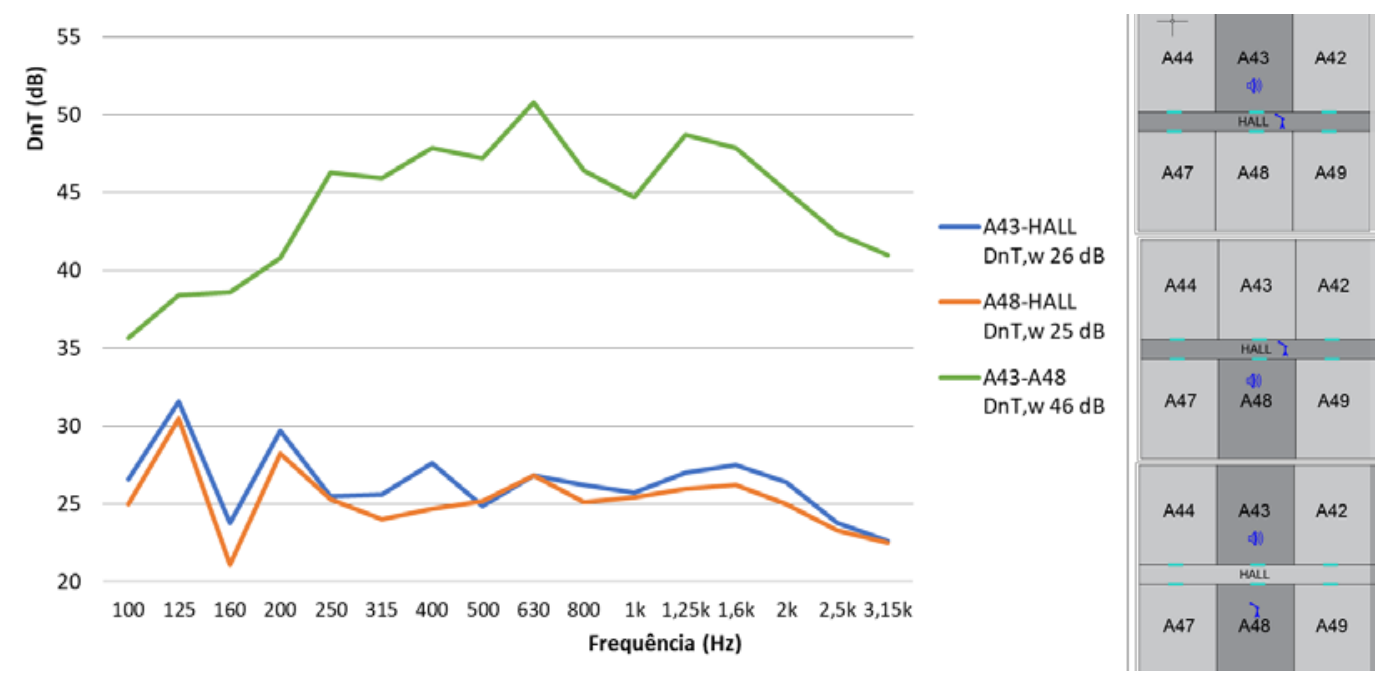

Figura 8 - Resultados entre os ambientes: A43-A48, A43-A47 e A43-A49
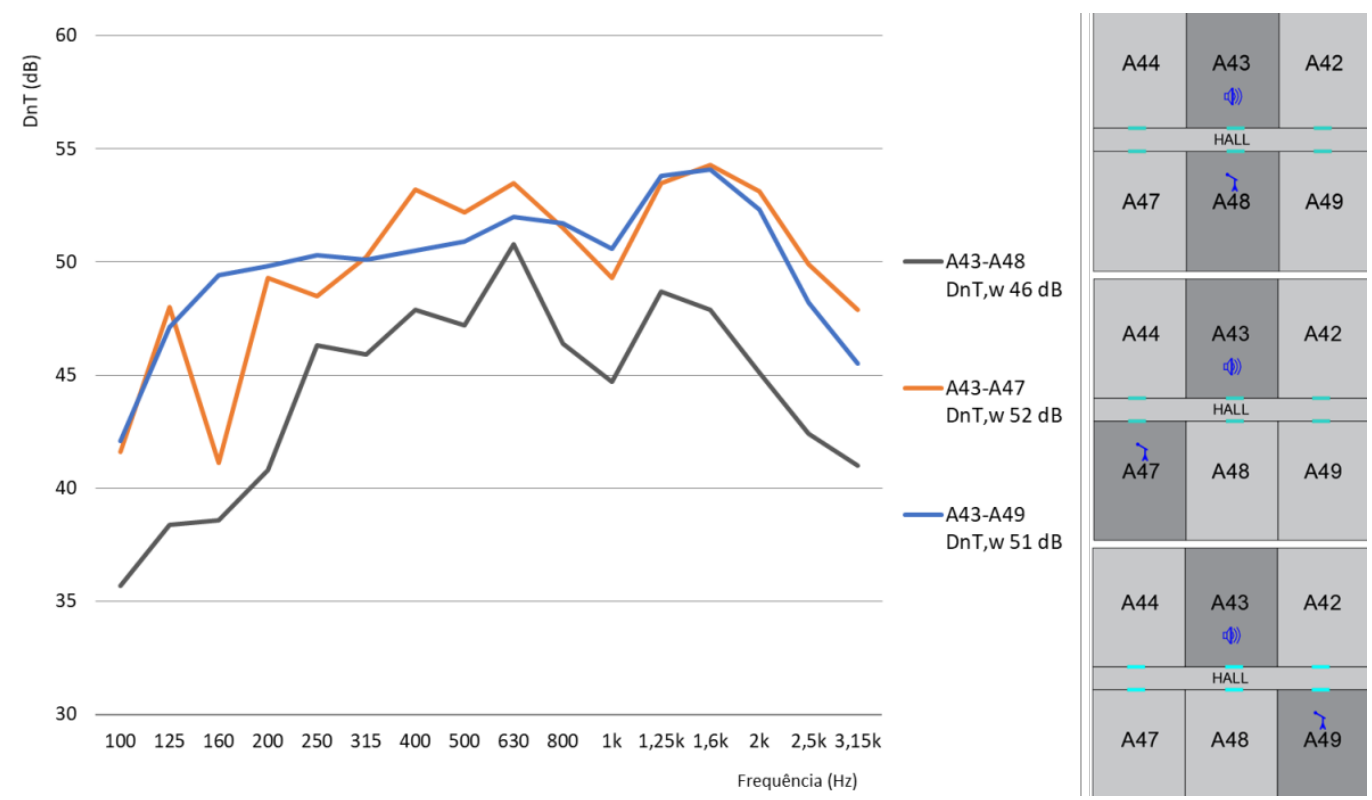
Figura 9 - Resultados entre ambientes: A53-hall, A58-hall e A53-A58

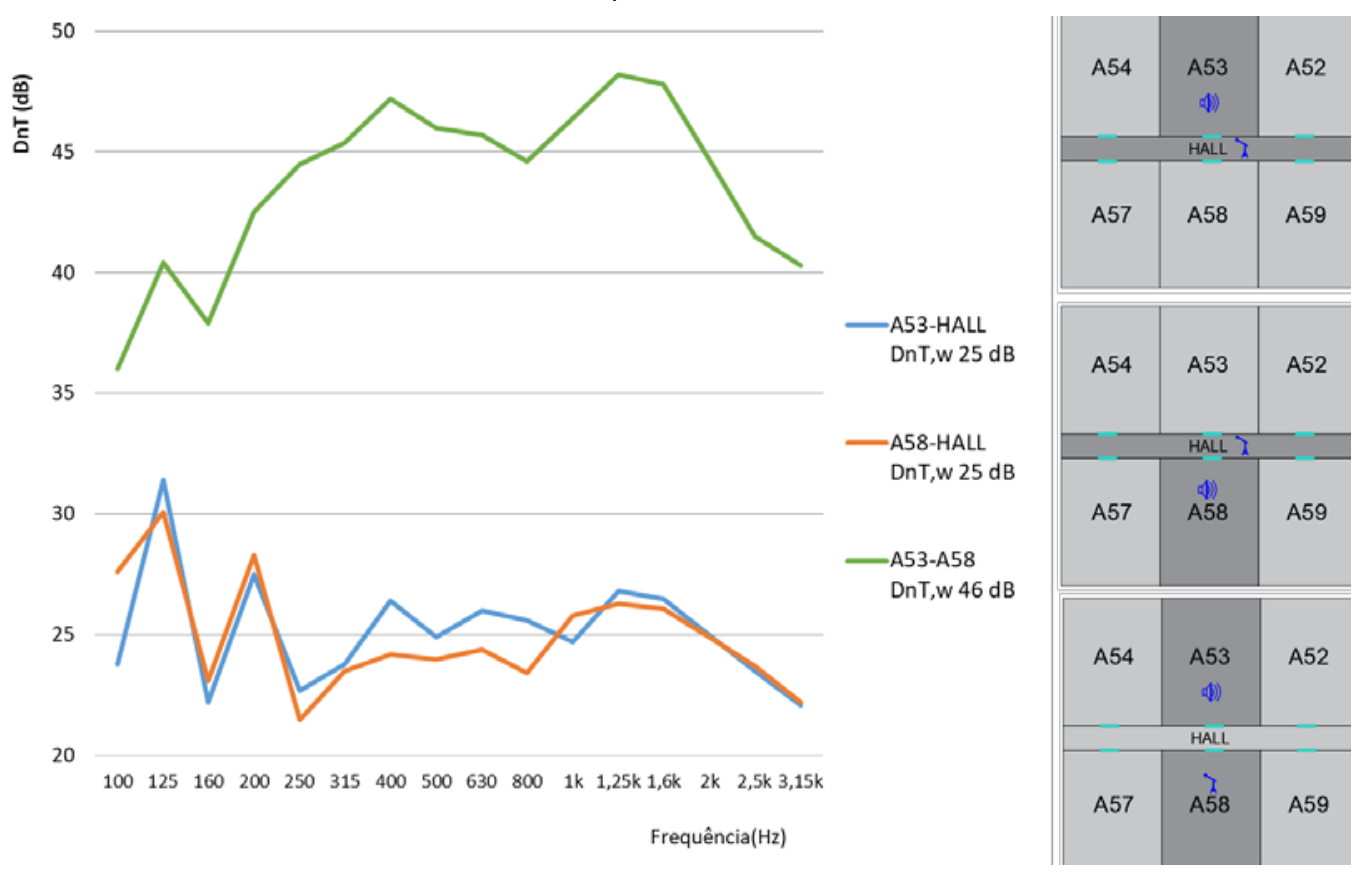

\section{Prédio B}

No prédio $B$ os ensaios foram realizados no segundo pavimento, nas situações de unidades habitacionais e o hall e entre unidades habitacionais em lados opostos do hall.

\section{Ensaios realizados no 20 pavimento}

A seguir é apresentado o isolamento ao ruído aéreo entre o apartamento B21 e o hall de entrada, entre o apartamento B22 e o hall de entrada, e entre os apartamentos B22 e B21, separados pelo hall de entrada, conforme demonstrado na Figura 10.

Comparando-se o isolamento de B21-hall com B22hall, observa-se uma diferença de $2 \mathrm{~dB}$ no valor global, em função da fresta de 7,27 mm do B21-hall, menor que no B22-hall, em que a fresta é de 8,82 $\mathrm{mm}$. Ainda, o isolamento entre unidades separadas pelo hall de entrada B22-B21 foi de $41 \mathrm{~dB}$, menor do que no prédio $\mathrm{A}$, de $46 \mathrm{~dB}$. Isso pode ser explicado pelo tempo de reverberação do hall do prédio $\mathrm{B}$, bem maior que o prédio $\mathrm{A}$, e pela sua geometria.

A curva do isolamento entre B22-B21 seguiu o mesmo padrão das curvas de B21-hall e B22-hall, com a perda acentuada de isolamento a partir da banda de $1.600 \mathrm{~Hz}$, em função das frestas das portas, conforme indicado em estudos de Hopkins (2012), Lo Verde e Dong (2013) e Labres et al. (2018).

\section{Prédio C}

Os ensaios no prédio $\mathrm{C}$ foram realizados em dois pavimentos entre unidades habitacionais e o hall, entre unidades habitacionais em lados opostos do hall e unidades habitacionais adjacentes laterais. Além disso, em um dos pavimentos foi utilizado um dispositivo móvel para vedação da fresta da porta de uma das unidades habitacionais.

\section{Ensaios realizados no 20 pavimento}

A Figura 11 ilustra os resultados dos ensaios no $2^{\circ}$ pavimento do prédio C.

O isolamento ao ruído aéreo entre o apartamento C23 e o hall e entre o apartamento C24 e o hall apresentam um comportamento muito semelhante, com uma frequência de ressonância na banda de 160 $\mathrm{Hz}$, o que também acontece quando o isolamento é medido entre as unidades separadas pelo hall de entrada. O isolamento entre C23-hall e C24-hall apresentou uma diferença de $2 \mathrm{~dB}$, o que é explicado pela existência das frestas abaixo das portas. No primeiro caso, a fresta tem espessura média de 8,63 mm, e no segundo caso de 10,11 mm. Também foi realizado o ensaio entre C23-C24 e C24-C23, alternando a posição do ambiente emissor e receptor, a fim de verificar se haveria diferença significativa nos resultados. As diferenças por bandas de frequências foram em geral de $1 \mathrm{~dB}$, chegando a $1,8 \mathrm{~dB}$ na banda de $800 \mathrm{~Hz}$. No entanto, o valor do isolamento global não se alterou com o resultado de $45 \mathrm{~dB}$. Nos ensaios entre apartamentos e hall se observou uma queda no isolamento a partir da banda de $1.000 \mathrm{~Hz}$, enquanto nas situações entre 
apartamentos separados pelo hall essa queda ocorreu de forma mais acentuada na banda de 1.600 $\mathrm{Hz}$, apresentando uma estabilização até a banda de $3.150 \mathrm{~Hz}$.

\section{Ensaios realizados no 3ำ pavimento}

No $3^{\circ}$ pavimento foram realizados ensaios entre as unidades e o hall de entrada e entre as unidades separadas pelo hall de entrada, com e sem o uso do dispositivo móvel de veda-porta nas frestas, como se observa na Figura 12.

Figura 10 - Resultados entre ambientes: B21-hall, B22-hall e B22-B21
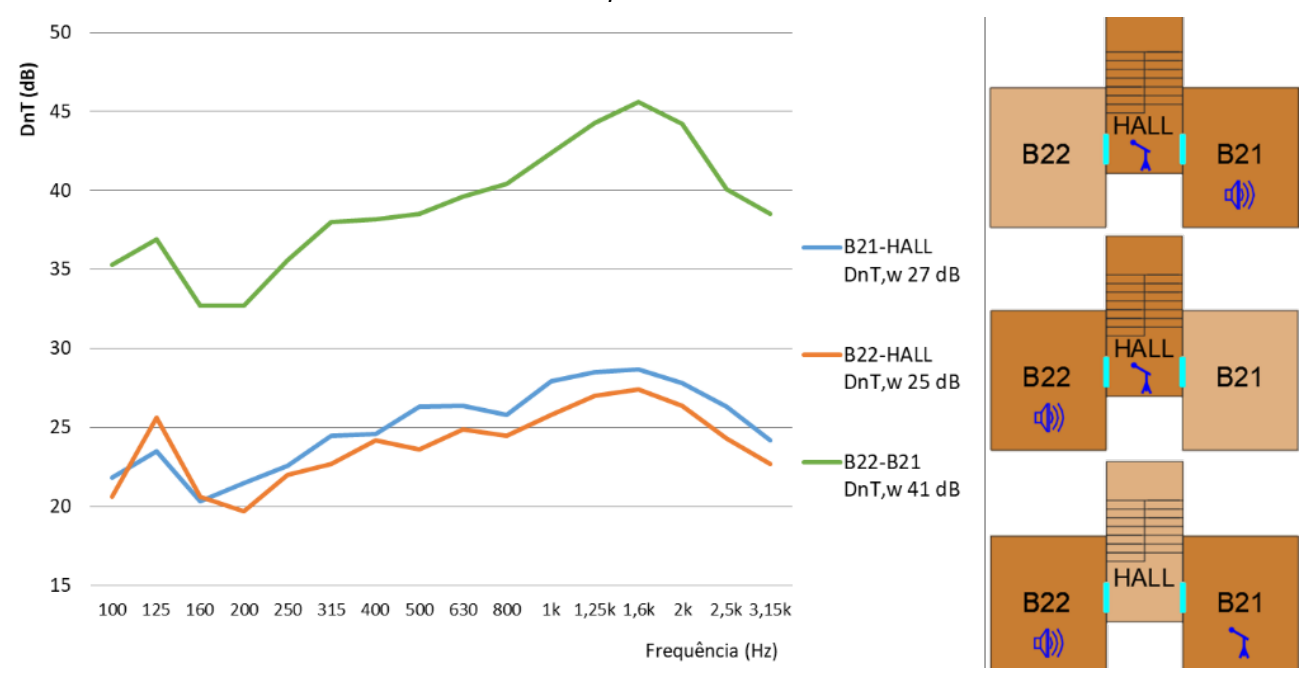

Figura 11 - Resultados entre os ambientes: C23-hall, C24-hall e C23-C24
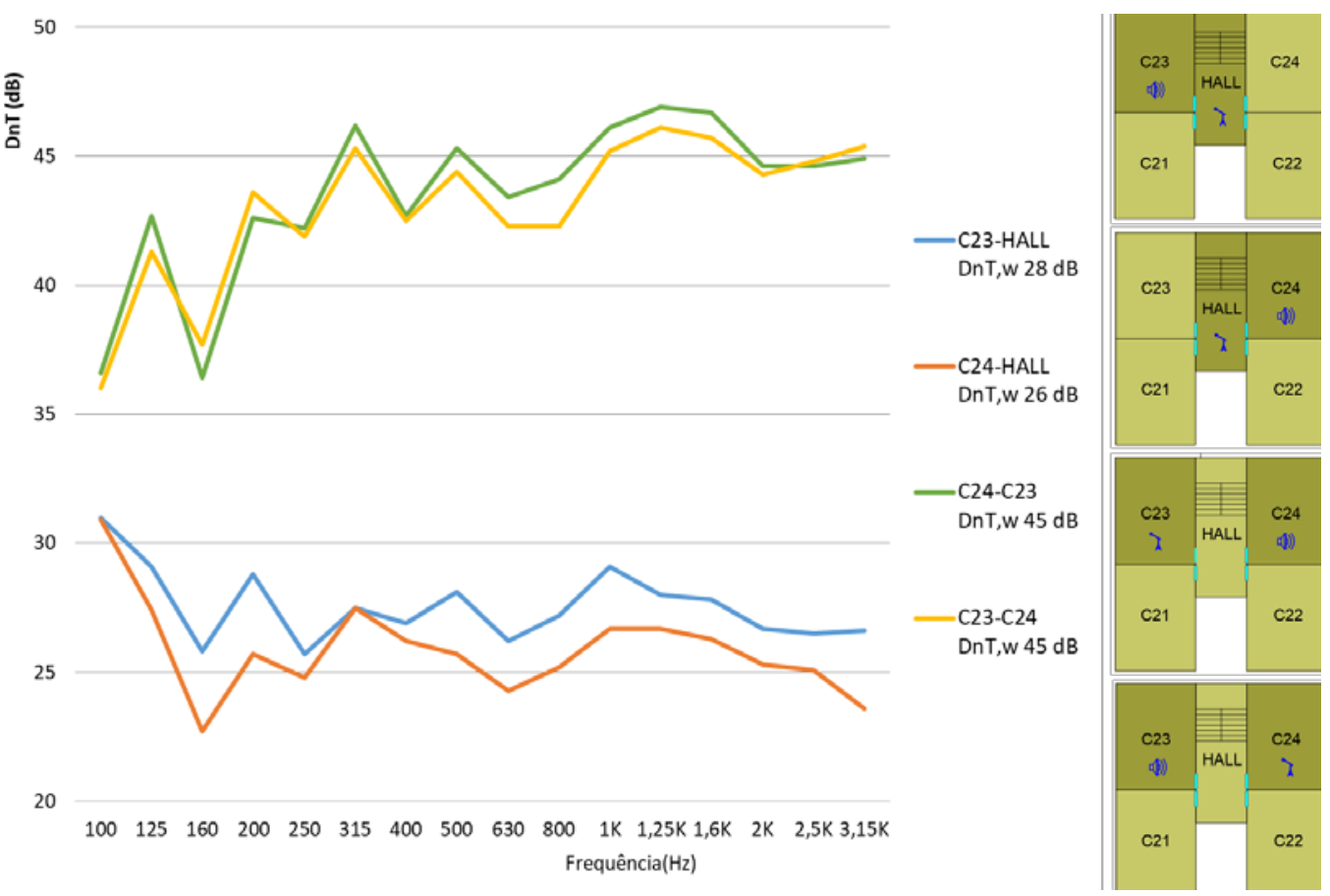
Figura 12 - Resultados entre os ambientes: C33-hall, C34-hall e C34-C33
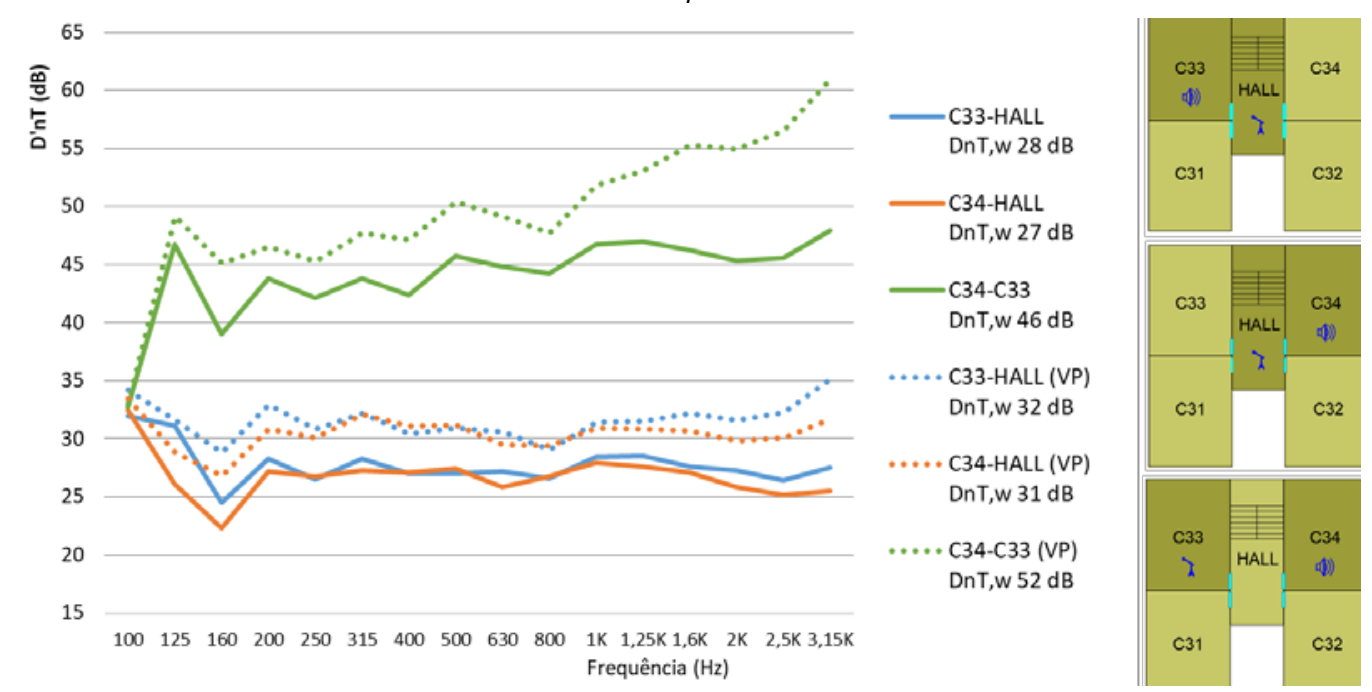

Pode-se observar o aumento no isolamento com o uso do veda-porta nas frestas, o que garantiu um acréscimo no valor global do isolamento de $4 \mathrm{~dB}$ para a situação entre apartamentos e hall, e $6 \mathrm{~dB}$ para o isolamento entre apartamentos separados pelo hall. Comparando-se as curvas de isolamento entre apartamento e hall com e sem o veda-porta, observa-se que o comportamento delas segue o mesmo padrão até a banda de $1.250 \mathrm{~Hz}$, a partir desse ponto as curvas dos sistemas com as portas sem o tratamento passam a cair e as curvas das portas com o veda-porta têm uma leve melhora, em coerência com os estudos de Hopkins (2012), Lo Verde e Dong (2013) e Labres et al. (2018). No valor do isolamento, considerando-se os apartamentos separados pelo hall, esse comportamento é mais acentuado, o isolamento é crescente a partir da banda de $800 \mathrm{~Hz}$ com o uso da vedação. Em todos os casos se observou a ressonância do sistema na banda de $160 \mathrm{~Hz}$. Quanto à diferença de $1 \mathrm{~dB}$ no isolamento entre C33-hall e C34-hall, nas duas situações, com e sem o uso do dispositivo de vedação, pode ser explicada pela fresta da porta, $8,37 \mathrm{~mm}$ no primeiro caso e 9,83 $\mathrm{mm}$ no segundo caso. Ao se comparar o isolamento entre as unidades separadas pelo hall, percebeu-se um ganho no isolamento a partir da banda de 800 $\mathrm{Hz}$, nas médias e altas frequências, com diferenças superiores a $10 \mathrm{~dB}$ nas bandas de frequências de $2.500 \mathrm{~Hz}$ e $3.150 \mathrm{~Hz}$.

\section{Comparação de ensaios realizados entre apartamentos e hall}

Ao comparar os gráficos de isolamento dos ensaios realizados entre os apartamentos e o hall de entrada, percebe-se uma frequência de ressonância na banda de $160 \mathrm{~Hz}$ nos quatro casos. A partir da banda de $1.000 \mathrm{~Hz}$ o isolamento começa a cair em função dos comprimentos de onda menores em face das frestas das portas. Porém, nas situações em que foi utilizado dispositivo veda-portas, a partir dessa banda de frequências o isolamento permaneceu estável e até apresentou um crescimento a partir da banda de $2.000 \mathrm{~Hz}$. Em relação às frestas, as situações com frestas na faixa dos $8 \mathrm{~mm}$ apresentaram resultado global de $28 \mathrm{~dB}$, a situação com fresta de $9,83 \mathrm{~mm}$ apresentou resultado de 27 $\mathrm{dB}$ e a porta com fresta de $10,11 \mathrm{~mm}$ resultou em um isolamento de $26 \mathrm{~dB}$. As situações com o uso do veda-porta obtiveram um ganho de $4 \mathrm{~dB}$ em relação ao original, com isolamentos de $32 \mathrm{~dB}$ e $31 \mathrm{~dB}$.

A seguir é apresentado um gráfico com os resultados de ensaios realizados entre apartamentos e o hall de entrada, com e sem o uso do dispositivo de vedação (Figura 13).

\section{Comparação de ensaios realizados entre apartamentos separados pelo hall de entrada}

Ao comparar as curvas de isolamento de todas as situações do prédio C entre apartamentos separados pelo hall, pode-se observar um comportamento similar quando não existe parede de geminação entre as unidades, como é o caso de C34-C32. Comparando-se a mesma situação C24-C23 e C34C33, em pavimentos diferentes, tem-se $1 \mathrm{~dB}$ de diferença no resultado do segundo caso, o que pode ser explicado pelos isolamentos obtidos entre as unidades e o hall, $28 \mathrm{~dB}$ e $26 \mathrm{~dB}$ no primeiro caso e $28 \mathrm{~dB}$ e $27 \mathrm{~dB}$ no segundo.

A seguir é apresentado um gráfico comparativo entre todos os ensaios realizados entre os apartamentos separados pelo hall de entrada (Figura 14). 
Figura 13 - Isolamento ao ruído aéreo entre apartamentos e hall de entrada do prédio C

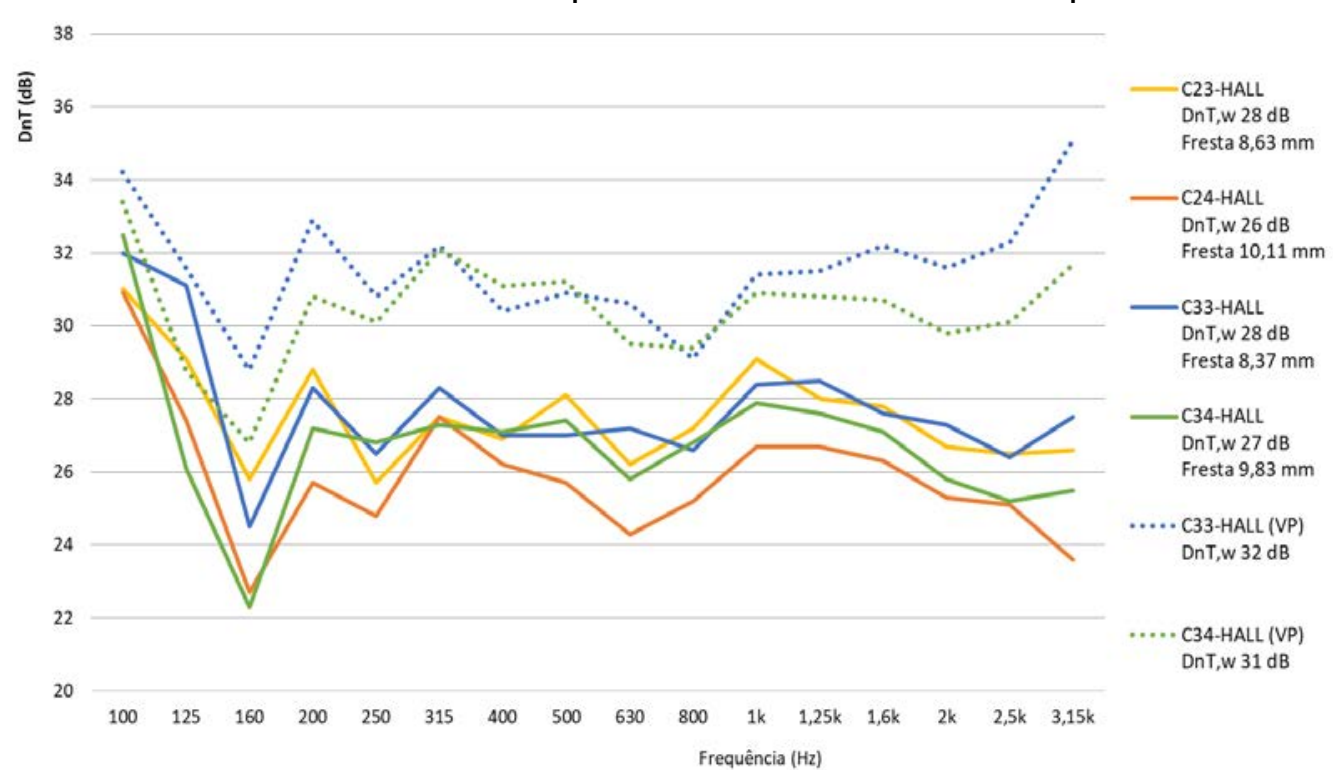

Figura 14 - Isolamento ao ruído aéreo entre apartamentos, separados pelo hall do prédio C

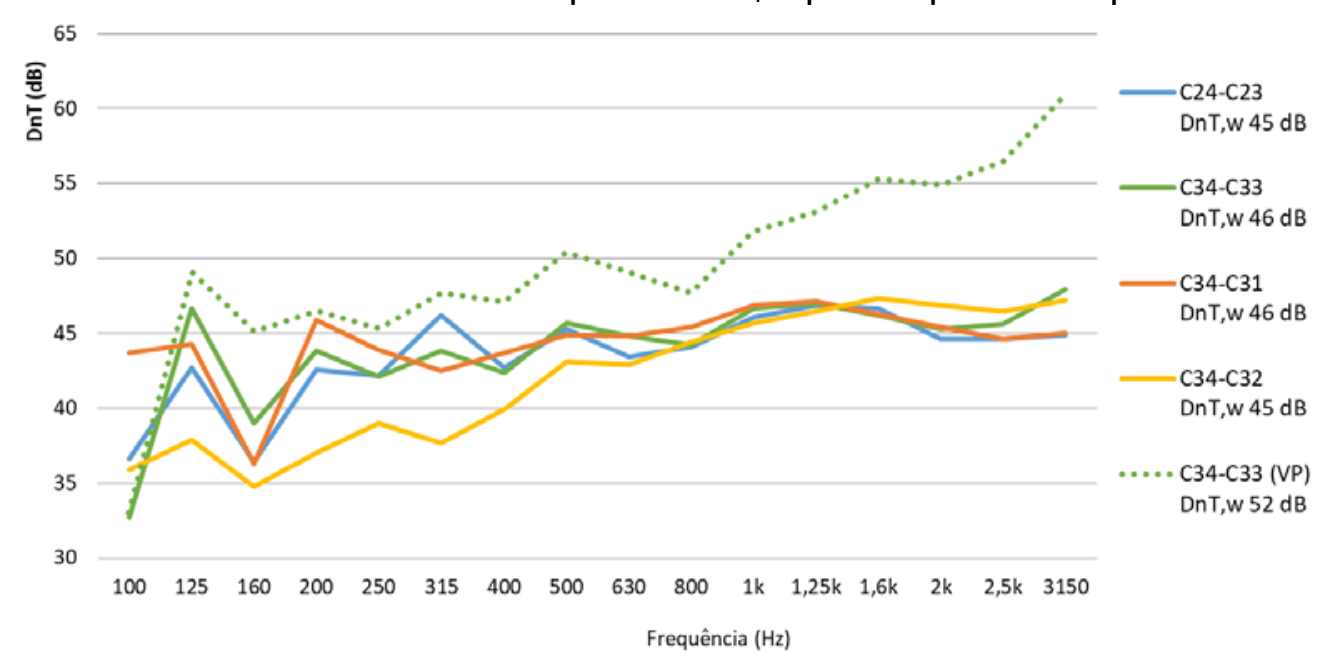

Apesar de considerar que o campo sonoro no ambiente emissor deveria ser difuso, a parede localizada na entrada tem influência no resultado final do isolamento acústico entre as unidades separadas pelo hall de entrada.

\section{Avaliação de desempenho segundo a NBR 15575}

A NBR 15575-4 (ASSOCIAÇÃO..., 2013b) estabelece os seguintes valores de referência para os desempenhos de conjuntos de paredes e portas de unidades distintas separadas pelo hall (Tabela 7).

Na Figura 15 são apresentados os valores obtidos em cada conjunto e a sua classificação de desempenho segundo a NBR 15575-4 (ASSOCIAÇÃO..., 2013b).
As classificações de desempenho superior foram constatadas para as composições em que as portas das unidades habitacionais distintas não estavam alinhadas, A43-A47 e A43 e A49, e para a composição com uso do dispositivo móvel de vedaporta C34-C33 (VP). Destaca-se que o aumento no isolamento sonoro com uso do dispositivo de vedaporta foi de $7 \mathrm{~dB}$ e que o ganho com o não alinhamento das portas foi entre 5 e $6 \mathrm{~dB}$ no $\mathrm{D}_{\mathrm{nT}, \mathrm{w}}$. Conforme mencionado, o isolamento acústico nas situações de adjacência lateral, A48-A47 e A48A49, foi influenciado pelas características de perda de transmissão sonora da parede de divisão entre unidades habitacionais e não permite uma conclusão sobre o não alinhamento frontal das portas de entrada. 
Tabela 7 - Classificação de desempenho entre apartamentos separados pelo hall de entrada

\begin{tabular}{l|c|c}
\hline \multicolumn{1}{c|}{ Elemento } & $\mathbf{D}_{\mathbf{n T , w}}$ (dB) & Nível de desempenho \\
\hline \multirow{2}{*}{$\begin{array}{l}\text { Conjunto de paredes e portas de } \\
\text { unidades distintas separadas pelo hall }\end{array}$} & 40 a 44 & Mínimo \\
\cline { 2 - 3 } & 45 a 49 & Intermediário \\
\cline { 2 - 3 } & $\geq 50$ & Superior \\
\hline
\end{tabular}

Fonte: ABNT (ASSOCIAÇÃO..., 2013b).

\section{Figura 15 - Valores obtidos em cada ensaio e respectiva classificação de desempenho acústico}

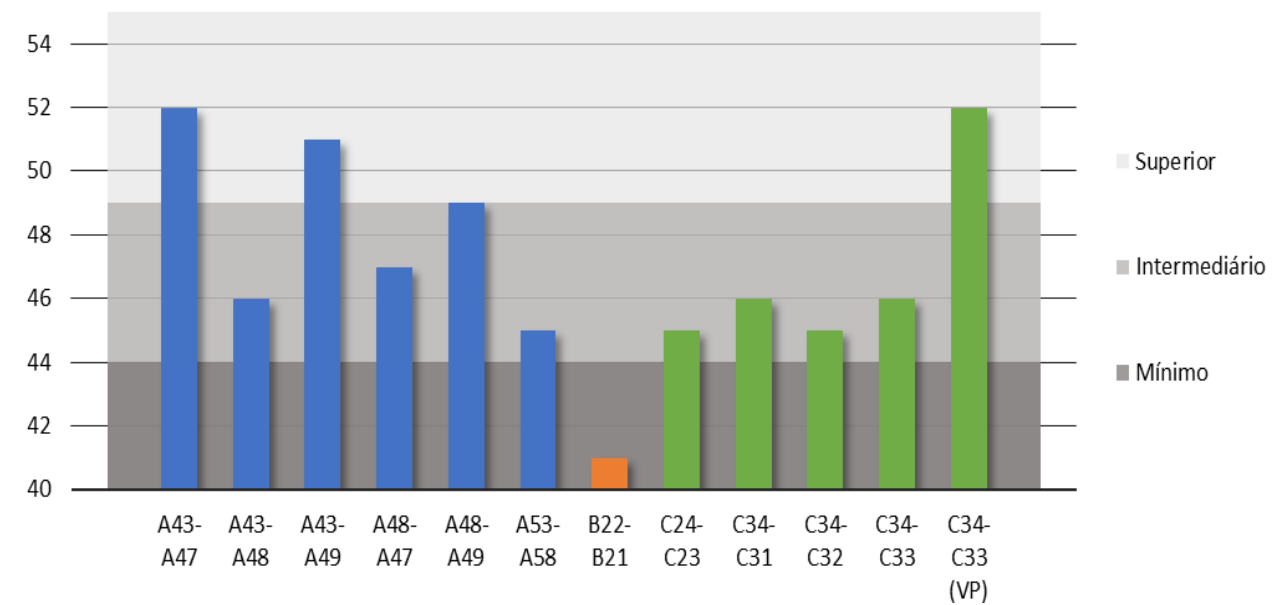

\section{Comparações entre resultados dos três prédios}

A média do tempo de reverberação $T$ é calculada conforme a ISO 3382-1 (INTERNATIONAL..., 2009), para as bandas de frequências entre $400 \mathrm{~Hz}$ e $1.250 \mathrm{~Hz}$. A relação entre tempo de reverberação do hall e isolamento acústico do conjunto de porta e parede também pode ser analisada com base na média do tempo de reverberação na Figura 16.

Pode-se verificar que o menor tempo de reverberação médio do prédio A está relacionado aos maiores valores do isolamento acústico, especialmente nos casos em que as portas das unidades habitacionais não estavam alinhadas (A43-47, A4-49 e A48-49). Essa situação está relacionada à maior influência do campo reverberante quando a distância entre a fonte e o receptor aumenta, conforme apresentado por Hopkins (2012). No prédio B, em que se verificou o menor isolamento acústico, o tempo de reverberação médio no hall foi, aproximadamente, $50 \%$ maior que no hall do prédio $\mathrm{A}$. No prédio $\mathrm{C}$ essa influência não foi verificada devido ao menor comprimento da circulação, mas é possível verificar a influência da vedação das frestas, com um aumento de $6 \mathrm{~dB}$ no isolamento do conjunto.
De modo geral, o isolamento acústico entre unidades separadas pelo hall de entrada dos três prédios estudados está relacionado às características dimensionais dos ambientes. $\mathrm{O}$ prédio $\mathrm{A}$ tem a circulação mais estreita, o que a princípio poderia justificar um isolamento acústico inferior ao do prédio $C$, em que as portas estão bem mais afastadas. Nos dois casos o isolamento entre unidades e hall foi similar. O hall do prédio $\mathrm{B}$ apresentou o maior tempo de reverberação, bem superior aos outros dois edifícios (Figura 17), e também o menor volume, o que pode explicar o desempenho inferior aos demais.

No prédio $\mathrm{C}$ se observou um aumento do isolamento a partir da banda de $2.500 \mathrm{~Hz}$, enquanto nos resultados dos outros sistemas pode-se verificar um decréscimo. Isso pode ser influenciado pela largura da circulação, tempo de reverberação e volume do hall, conforme se observa na Figura 18.

Ainda, notou-se que o prédio $\mathrm{B}$ tem a menor área total do conjunto porta e parede, para o qual a relação porta/parede é de 31\% (Tabela 8).

Por fim, ao se analisar o isolamento acústico entre unidades habitacionais e o hall de entrada nos três prédios (Figura 19), pode-se verificar que os valores de $\mathrm{D}_{\mathrm{nT}, \mathrm{w}}$ variam de $25 \mathrm{~dB}$ a $28 \mathrm{~dB}$ e são fortemente influenciados pela espessura média das frestas. 
Figura 16 - Relação entre tempo de reverberação e $D_{n T, w}$ dos três edifícios

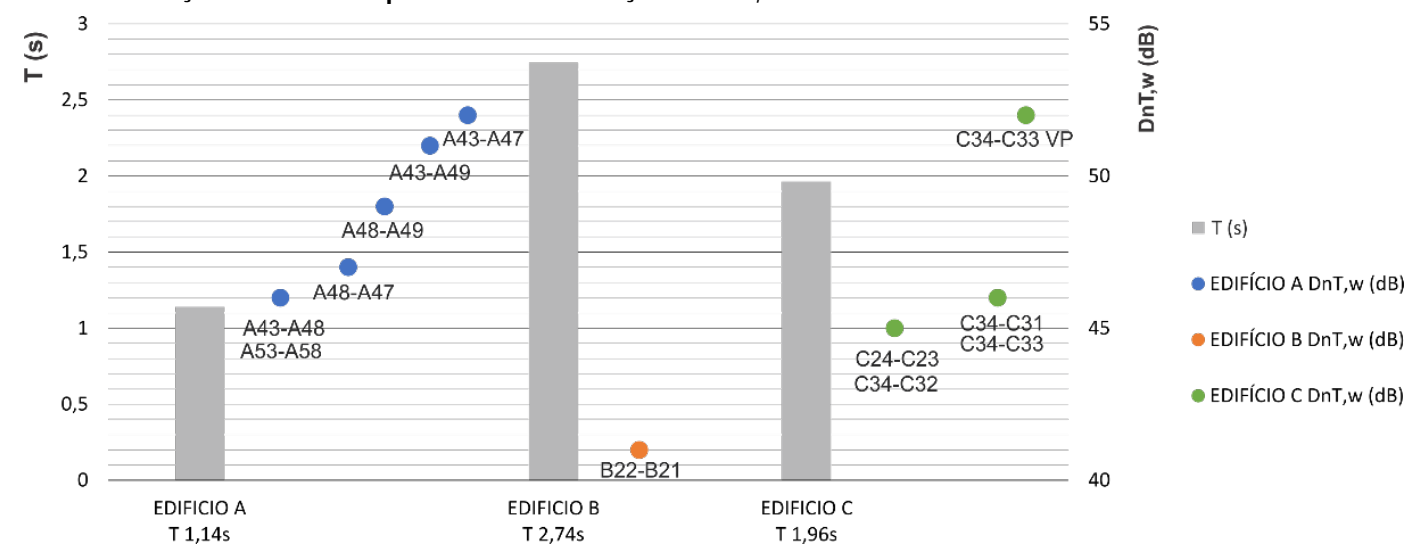

Figura 17 - Tempo de reverberação no hall dos três edifícios

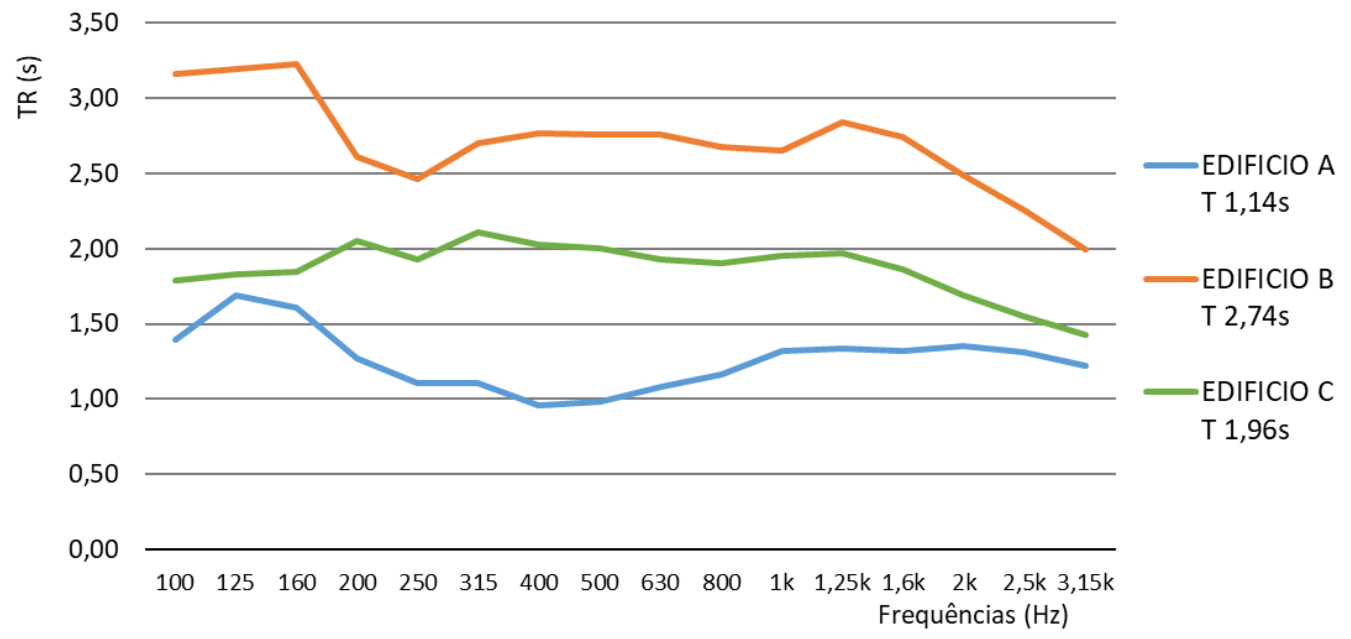

Figura 18 - Isolamento ao ruído aéreo entre apartamentos com portas alinhadas

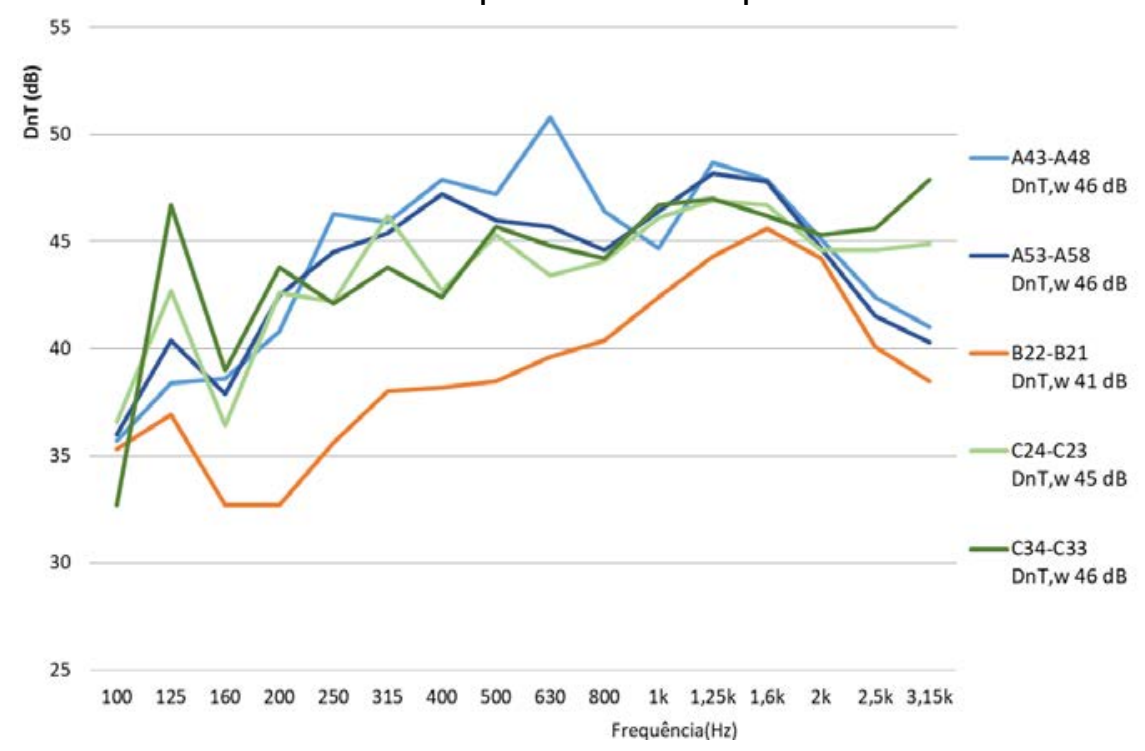


Tabela 8 - Relação dos conjuntos porta/parede

\begin{tabular}{c|c|c|c|c|c|c}
\hline Prédio & $\begin{array}{c}\text { Área total do } \\
\text { conjunto }\left(\mathbf{m}^{\mathbf{2}}\right)\end{array}$ & $\begin{array}{c}\text { Área da } \\
\text { parede }\left(\mathbf{m}^{\mathbf{2}} \mathbf{)}\right.\end{array}$ & $\begin{array}{c}\text { Área da } \\
\text { porta }\left(\mathbf{m}^{\mathbf{2}}\right)\end{array}$ & $\begin{array}{c}\text { Relação } \\
\text { porta/parede }\end{array}$ & $\begin{array}{c}\text { Largura da } \\
\text { circulação } \\
\mathbf{( m )}\end{array}$ & $\begin{array}{c}\text { Volume da } \\
\text { circulação } \\
\left(\mathbf{m}^{\mathbf{3}}\right)\end{array}$ \\
\hline $\mathrm{A}$ & 10,27 & 8,38 & 1,89 & $18 \%$ & 1,20 & 61,24 \\
$\mathrm{~B}$ & 6,08 & 4,19 & 1,89 & $31 \%$ & 2,37 & 28,60 \\
$\mathrm{C}$ & 13,37 & 11,69 & 1,68 & $12 \%$ & 2,50 & 40,02 \\
\hline
\end{tabular}

\section{Figura 19 - Isolamento ao ruído aéreo entre apartamentos, separados pelo hall}

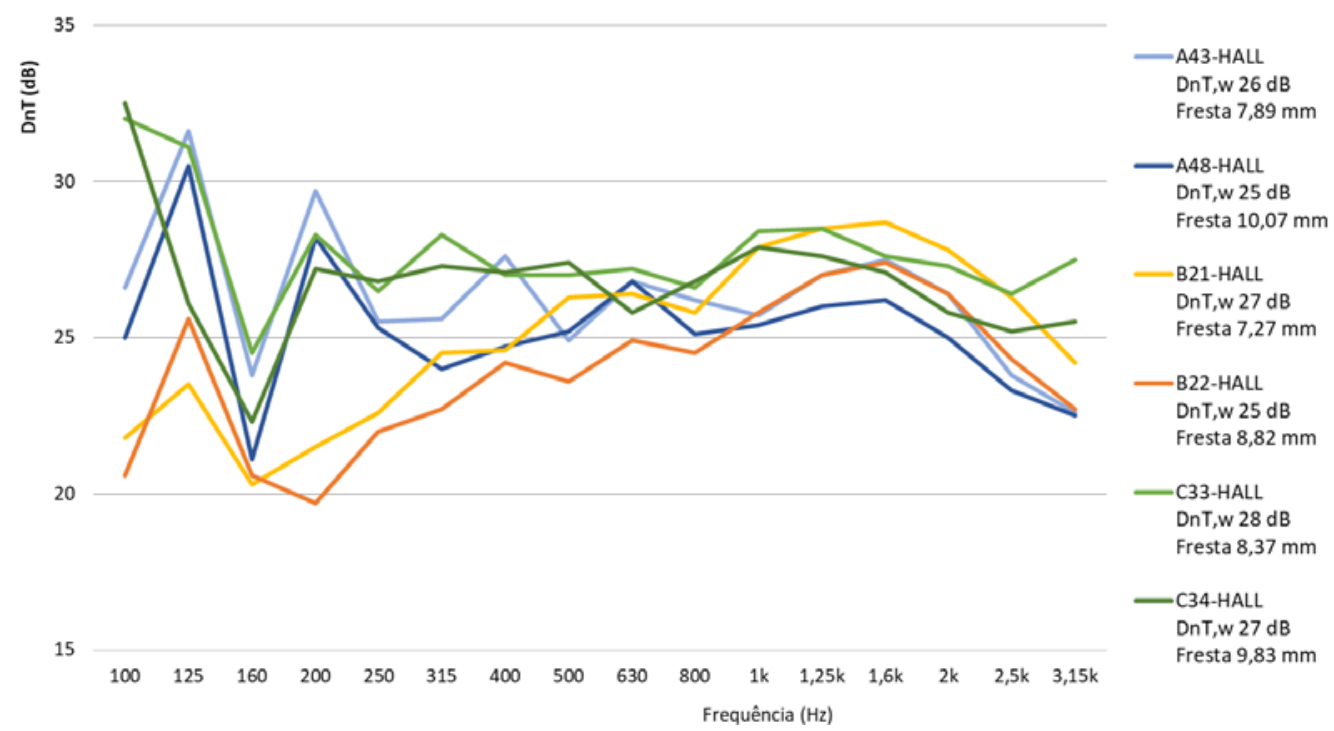

O efeito da ressonância na banda de $160 \mathrm{~Hz}$ pode ser verificado na maior parte dos resultados. De acordo com Hopkins (2012), a transmissão ressonante está relacionada ao acoplamento e é decorrente da radiação sonora e do acoplamento estrutural dos sistemas construtivos. No caso de caixilhos instalados em paredes, a transmissão ressonante pode estar sob o controle do amortecimento decorrente do tipo de instalação, que pode resultar em um mecanismo de perda dissipativa. Ainda, a parede na qual um caixilho está instalado representa um defletor rígido infinito. Nesse ponto, pode-se indicar uma complexidade maior nas estimativas teóricas da perda de transmissão ressonante, porque as perdas do acoplamento estrutural para uma junção específica são difíceis de calcular com precisão. Além disso, para as paredes de alvenaria, consideradas ortotrópicas, com seus limites compostos de junções rígidas, o fator de perda do acoplamento médio para os limites da placa ocorre de forma distinta para as diferentes direções de transmissão sonora. Assim, conforme indica Hopkins (2012), aceita-se que, embora seja possível estimar algumas partes do fator de perda total no isolamento acústico desse tipo de sistema construtivo, não é possível a estimativa e consequente justificativa de todas elas.

\section{Conclusões}

Os ensaios em campo para a verificação do desempenho de sistemas construtivos assumem cada vez mais relevância para avaliações do comportamento de diferentes elementos construtivos combinados entre si, com diferentes tipos de instalações. Neste trabalho, o desempenho acústico de conjuntos de paredes e portas de unidades habitacionais distintas separadas pelo hall foi avaliado a partir de ensaios em campo, para os quais se pode analisar as diferenças obtidas com as composições estudadas.

A influência das circulações de uso comum, das frestas das portas e do alinhamento das portas de unidades habitacionais distintas no isolamento sonoro foi determinada para fins de classificação do desempenho acústico, conforme a atual NBR 15575. A vedação das frestas das portas é indicada como a medida mais eficiente para a qualificação do isolamento acústico de conjuntos de portas e paredes separadas pelo hall, sendo verificado neste trabalho o aumento de $7 \mathrm{~dB}$ no $\mathrm{D}_{\text {nT,w. }} \mathrm{O}$ não alinhamento das portas de entrada de unidades habitacionais distintas, separadas pelo mesmo hall é indicado como o segundo fator de maior influência, com aumentos entre 4 e $5 \mathrm{~dB}$ no $\mathrm{D}_{\mathrm{nT}, \mathrm{w}}$. 
Foi constatado que o afastamento das portas e o não alinhamento entre elas acarreta maiores valores de isolamento acústico do conjunto. A pior situação foi verificada quando as portas estão alinhadas, de frente uma para a outra. Quando se faz o ensaio entre dois apartamentos localizados um ao lado do outro, o resultado é comparativamente inferior, em função da influência do isolamento acústico da parede de geminação. O isolamento acústico ao ruído aéreo nas situações estudadas também foi fortemente influenciado pelo tempo de reverberação da circulação. Dessa forma, pode-se também concluir que mesmo as portas não estando alinhadas, o controle do tempo de reverberação do hall é uma solução eficiente para o aumento do desempenho acústico do conjunto.

Após a série de ensaios realizados nos três prédios residenciais, ficou evidenciado que as frestas das portas têm uma influência determinante no isolamento aéreo do conjunto, tanto entre as unidades habitacionais e o hall de entrada como entre duas unidades habitacionais separadas pelo hall. No isolamento das unidades habitacionais para o hall de entrada, obtiveram-se valores muito parecidos, variando entre $25 \mathrm{~dB}$ e $28 \mathrm{~dB}$ nos três casos, todos com frestas próximas a $10 \mathrm{~mm}$.

\section{Referências}

ANTÓNIO, J.; TADEU, A.; GODINHO, L. Analytical Evaluation of the Acoustic Insulation Provided by Double Infinite Walls. Journal of Sound and Vibration, v. 263, p. 113-129, 2003.

ASSOCIAÇÃO BRASILEIRA DE NORMAS TÉCNICAS. NBR 15575-1: edificações habitacionais: desempenho: parte 1: requisitos Gerais. Rio de Janeiro, 2013a.

\section{ASSOCIAÇÃO BRASILEIRA DE NORMAS} TÉCNICAS. NBR 15575-4: edificações habitacionais: desempenho: parte 4: requisitos para os sistemas de vedações verticais internas e externas - SVVIE. Rio de Janeiro, 2013b.

CHO, W. H. et al. Best Practice for Positioning Sound Absorbers at Room Surface. Applied Acoustics, v. 129, p. 306-315, 2018.

DUARTE, E.; VIVEIROS, E. Desempenho Acústico na Arquitetura Residencial Brasileira: paredes de vedação. Ambiente Construído, Porto Alegre, v. 7, n. 3, p. 159-171, jul./set. 2007.

EGAN, D. Architectural Acoustics. New York: McGraw-Hill, 2014.
GARG, N.; KUMAR, A.; MAJI, S. Significance and Implications of Airborne Sound Insulation Criteria in Building Elements for Traffic Noise Abatement. Applied Acoustics, v. 74, n. 12, p. 1.429-1.435, 2013.

HASSAN, O. A. B. Building Acoustics and Vibration: theory and practice. London: World Scientific, 2009.

HERRERA, J. M.; RECUERO, M. Influence of Seal Installation to Predict Sound Insulation of Double Panel Steel Doors. Building and Environment, v. 45, n. 4, p. 1.087-1.094, 2010.

HONGISTO, V. Airbourne Sound Insulation of Wall Structures-Measurements and Prediction Methods. Helsinki: Helsinki University of Technology, 2000.

HOPKINS, C. Sound Insulation. Burlington: Elsevier, 2012.

INTERNATIONAL ORGANIZATION FOR STANDARDIZATION. ISO 16283-1: acoustics: field measurement of sound insulation in buildings and of buildings elements: part 1: airborne sound insulation. Genebra, 2014.

\section{INTERNATIONAL ORGANIZATION FOR} STANDARDIZATION. ISO 3382-19: acoustics: measurement of room acoustic parameters: part 1: performance spaces. Genebra, 2009.

INTERNATIONAL ORGANIZATION FOR STANDARDIZATION. ISO 3382-2: acoustics: measurement of room acoustic parameters: part 2: reverberation time in ordinary rooms. Genebra, 2008.

\section{INTERNATIONAL ORGANIZATION FOR} STANDARDIZATION. ISO 717-1: acoustics: rating of sound insulation in buildings and of building elements: part 1: airborne sound insulation. Genebra, 2013.

JONES, D. Acoustical Noise Control. In: BALLOU, G. (Org.). Handbook for Sound Engineers. Oxford: Taylor \& Francis, 2008.

KLIPPEL FILHO, S. et al. Desempenho Acústico em Um Edifício Residencial: classificação superior pela NBR 15575. Acústica e Vibrações, v. 48, p. 93-103, 2016.

LABRES, H. S. et al. Acoustic Performance of Brick Masonry Walls: construction defects and influence of installations. Building Acoustics, v. 25, n. 4, 2018.

LO VERDE, J.; DONG, W. Evaluation of Proposed ASTM Standard to Measure the Normalized Insertion Loss of Doors. Acoustical Society of America, v. 19, n. 040147, 2013. 
MAK, C. M.; WANG, Z. Recent Advances in Building Acoustics: an overview of prediction methods and their applications. Building and Environment, v. 91, p. 118-126, 2015.

MATEUS, D. M. R.; PEREIRA, A. S. C. Influência de Pequenos Erros de Execução em Obra no Desempenho Acústico de edifícios: exemplos típicos. In: TECNIACUSTICA, Cáceres, 2011. Anais... Cáceres: SPA, 2011.

MATSUDA, T. et al. Experimental Study on Use of Sound Absorption Treatment for Reduction of Environmental Sound Propagation and Reverberation in Staircases: a case study in housing. Buildings, v. 7, n. 4, p. 14, 2017.

PATRÍCIO, J. V. Acústica de Edifícios: índices de isolamento a sons aéreos utilizados no espaço europeu. Revista de Acústica, v. 35, p. 5-12, 2005.

PATRÍCIO, J. V. Condicionamento Acústico de Estabelecimentos de Restauração e de Unidades Similares. 6. ed. Lisboa: LNEC, 2010.

PETERS, R. J.; SMITH, B. J.; HOLLINS, M. Acoustics and Noise Control. 3. ed. New Jersey: Taylor \& Francis, 2013.

PIÃO, A.; GODINHO, L.; TADEU, A.

Comportamento Acústico de Paredes de Alvenaria na Presença de Pequenas Aberturas e Diferentes Inclusões. In: TECNIACÚSTICA, Coimbra, 2008. Anais... Coimbra: SPA, 2008.
PRATO, A.; SCHIAVI, A. Sound Insulation of Building Elements at Low Frequency: a modal approach. Energy Procedia, v. 78, p. 128-133, 2015.

RASMUSSEN, B. Acoustic Classification Schemes in Europe: applicability for new, existing and renovated housing. In: BALTIC-NORDIC ACOUSTICS MEETING, Stockholm, 2016. Proceedings... Stockholm: Nordic Acoustic Association, 2016.

SCHIAVONI, S. et al. Insulation Materials for the Building Sector: a review and comparative analysis. Renewable and Sustainable Energy Reviews, v. 62, p. 988-1.011, 2016.

SCHVARSTZHAUPT, C. C.; TUTIKIAN, B. F.; NUNES, M. F. O. Análise Comparativa do Desempenho Acústico de Sistemas de Fachada Com Esquadrias de PVC Com Persiana e Diferentes Tipos de Vidros em Ensaios de Laboratório. Ambiente Construído, Porto Alegre, v. 14, n. 4, p. 135-145, out./dez. 2014.

THOMAS, D.; DING, G. Comparing the Performance of Brick and Timber in Residential Buildings: the case of Australia. Energy and Buildings, v. 159, p. 136-147, 2018.

ZANNIN, P. H. T. et al. Comparação Entre Tempos de Reverberação Calculados e Medidos. Ambiente Construído, Porto Alegre, v. 5, n. 4, p. 75-85, out./dez. 2005.

\section{Claudio Trindade Scherer}

PPG ArqUrb | Universidade do Vale do Rio dos Sinos | Av. Unisinos, 950, Cristo Rei | São Leopoldo - RS - Brasil | CEP 93022-750 | Tel.: (51) 3591-1122 | E-mail: claudio@mmcprojetos.com.br

\section{Maria Fernanda de OLiveira}

PPG ArqUrb e itt Performance | Universidade do Vale do Rio dos Sinos | E-mail: mariaon@unisinos.br

Daniel Reis Medeiros

PPG ArqUrb e itt Performance | Universidade do Vale do Rio dos Sinos | E-mail: drmedeiros@unisinos.br

Bernardo Fonseca Tutikian

PPG Arqurb e itt Performance | Universidade do Vale do Rio dos Sinos | E-mail: bftutikian@unisinos.br

\section{Revista Ambiente Construído}

Associação Nacional de Tecnologia do Ambiente Construído

Av. Osvaldo Aranha, 99 - 3o andar, Centro

Porto Alegre - RS - Brasil

CEP $90035-190$

Telefone: +55 (51) 3308-4084

Fax: +55 (51) 3308-4054

www. seer. ufrgs. br/ ambienteconstruido

E-mail: ambienteconstruido@ufrgs.br 